\title{
SingHealth Radiology Archives pictorial essay Part 2: gastroenterology, musculoskeletal, and obstetrics and gynaecology cases
}

\author{
Mark Bangwei $\operatorname{Tan}^{1}$, MRCS, FRCR, Kim Ping $\operatorname{Tan}^{1}$, FRCR, FAMS, Joey Chan Yiing Beh $^{2}$, MMed, FRCR, \\ Eugenie Yi Kar $\underline{\text { Chan }}{ }^{3}$, MBBS, Kenneth Fu Wen $\underline{C h i n}^{3}$, MD, Zong Yi $\underline{C h i n}^{3}$, MBChB, MRCs, Wei Ming $\underline{\text { Chua }}{ }^{3}$, MMed, FRCR, \\ Aaron Wei-Loong Chong ${ }^{3}$, MB BCh BAO, Gary Tianyu $\mathrm{Gu}^{3}$, MBBS, MRCS, Wenlu $\mathrm{Hou}^{3}$, MMed, FRCR, \\ Anna Chooi Yan Lai ${ }^{1}$, MMed, FRCR, Rebekah Zhuyi Lee ${ }^{3}$, MBBS, Perry Jia Ren Liew ${ }^{4}$, MMed, FRCR, \\ May Yi Shan $\underline{L i m}^{3}$, MRCS, FRCR, Joshua Li Liang $\underline{L i m}^{3}$, MBBS, Zehao $\operatorname{Tan}^{3}$, MMed, FRCR, Eelin $\operatorname{Tan}^{3}$, BMed, MD, \\ Grace Siew Lim $\underline{\operatorname{Tan}^{3}}$, MBBS, Timothy Shao Ern $\underline{\operatorname{Tan}^{3}}$, MBChB, Eu Jin $\underline{\operatorname{Tan}}{ }^{1}$, MMed, FRCR, \\ Alexander Sheng Ming Tan ${ }^{1}$, MRCS, FRCR, Yet Yen $\underline{Y a n}^{4}$, MMed, FRCR, Winston Eng Hoe $\underline{\mathrm{Lim}}^{1}$, FRCR, FAMS
}

\begin{abstract}
The Singapore Health Services cluster (SingHealth) radiology film archives are a valuable repository of local radiological cases dating back to the 1950s. Some of the cases in the archives are of historical medical interest, i.e. cerebral angiography in the workup of patients with hemiplegia. Other cases are of historical social interest, being conditions seen during earlier stages of Singapore's development, i.e. bound feet. The archives form a unique portal into the development of local radiology as well as the national development of Singapore. A selection from the archives is published in commemoration of the International Day of Radiology in 2020, as well as the 200th anniversary of the Singapore General Hospital in 2021. This pictorial essay comprises gastroenterology, musculoskeletal and obstetrics and gynaecology cases from the archives.
\end{abstract}

Keywords: archives, historical, national development, pictorial essay, SingHealth

\section{INTRODUCTION}

The Singapore Health Services (SingHealth) radiology film archives comprise radiography case records dating back to the 1950s. The archives are located within Singapore General Hospital (SGH) and comprise cases of historical medical interest as well as of historical social interest. The archives form a unique portal into the development of local radiology as well as the national development of Singapore. A selection from the archives is published here in commemoration of the International Day of Radiology in 2020, as well as the 200th anniversary of the Singapore General Hospital in 2021. This pictorial essay comprises gastroenterology, musculoskeletal and obstetrics and gynaecology cases from the archives. Part 1, which was published earlier, comprised cardiovascular, respiratory and neurological cases. ${ }^{(1)}$

\section{LEAD POISONING}

Fig. 1 is a radiograph of the knees of a child with altered mental state. It demonstrates the presence of dense metaphyseal bands, raising the concern of lead poisoning. This appearance arises because lead inhibits osteoclastic activity and enables unopposed osteoblastic activity, creating thick sclerotic bands. In the past, lead was frequently added to paint as a pigment and to increase its durability; paint with added lead was frequently used for painting houses and children toys. However, it was discovered that lead ingestion was associated with cognitive impairment and behavioural problems, and its use in paint was banned since 1978. Today, the use of lead persists in the manufacturing of various products such as solder, batteries and plastics. This film was donated by Dr Richard Gold from the University of California in San Francisco, California, United States (USA).

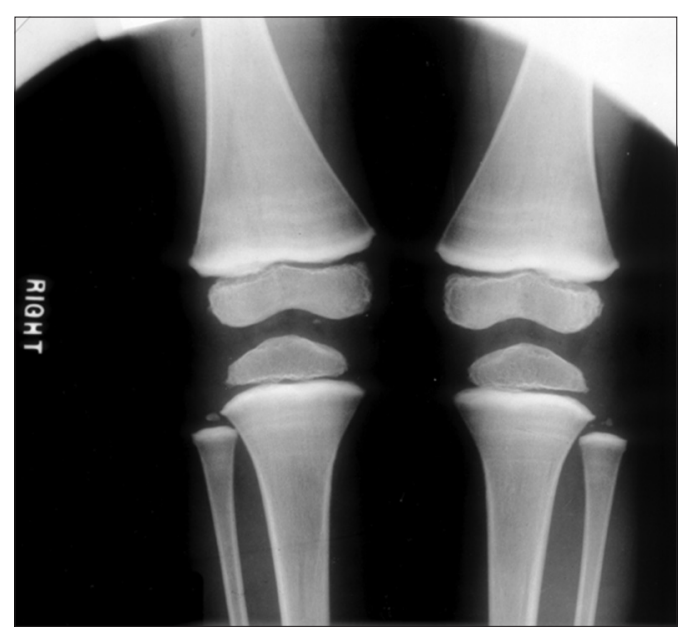

Fig. 1 Bilateral knee radiograph of a child with altered mental state shows the presence of dense metaphyseal bands, raising the concern of lead poisoning.

${ }^{1}$ Department of Diagnostic Radiology, Singapore General Hospital, ${ }^{2}$ Department of Radiology, Ng Teng Fong General Hospital, ${ }^{3}$ SingHealth Diagnostic Radiology Residency Programme, ${ }^{4}$ Department of Radiology, Changi General Hospital, Singapore

Correspondence: Dr Mark Tan Bangwei, Associate Consultant, Department of Diagnostic Radiology, Singapore General Hospital, Outram Road, Singapore 169608. marktanbangwei@gmail.com 
Although the origins of this film are unclear, it may be part of an academic collaboration that was initiated by Dr Boey Hong Khim, a well-known local radiologist in 1992, between Singapore and the Hospital of the University of Pennsylvania, the University of Utah, Stanford University and the Institute of Neurology in Phoenix, Arizona, USA.

\section{RUBELLA}

Fig. 2 is a bilateral knee radiograph of a neonate showing longitudinally oriented sclerotic striations. These extend from the metaphysis of both distal femurs and proximal tibias, and are more prominent in the femora, giving rise to a 'celery stalk' appearance. An incidental note is also made of the normal physiologic bowing of the bilateral lower limbs. Differential diagnoses include congenital infections such as rubella, syphilis and cytomegalovirus, as well as osteopathia striata. In this case, the diagnosis was rubella. Singapore had a rubella epidemic in 1969, then periodic outbreaks in the 1970s. Rubella vaccination was first introduced in Singapore in 1976. Currently, with the catch-up measles vaccination programme, the number of rubella cases has gradually declined from 10.9 cases per 100,000 population in 1999 to 3.6 per 100,000 population in 2009. The incidence of congenital rubella has been about 0-2 cases per year since $1995 . .^{(2)}$

\section{SYPHILIS}

A young man presented with right calf pain. Plain radiograph of the right tibia-fibula (Fig. 3) reveals anterior bowing of the right tibia at its mid diaphysis with associated cortical thickening, classically known as the 'sabre shin' deformity. This deformity is often found as a late manifestation of congenital syphilis, which was the case for this patient. A differential diagnosis for this appearance is Paget's disease. This develops as a sequelae of chronic periostitis and osteitis involving the tibia and is frequently bilateral. The recorded incidence of syphilis rose in post-war Singapore, partly from population and socioeconomic growth, ${ }^{(3)}$ but has seen many improvements in control over the years due to appropriate antibiotic therapy as well as efforts at contact tracing and health education. Cases of congenital syphilis are rare today, as routine venereal disease testing performed for mothers in the first trimester allows for early intervention.

\section{SCURVY}

A young child presented with non-specific joint pain. A radiograph of the lower limbs donated by the University of Kentucky to the SingHealth archives (Fig. 4) demonstrates typical radiological findings of hypovitaminosis C, commonly known as scurvy. A deficit in Vitamin $C$ results in defective collagen synthesis and commonly presents with impaired wound healing and bleeding diathesis. With the subsequent improvements in nutrition in developed countries, this disease has become rare. Typical radiological findings of scurvy ${ }^{(4)}$ include generalised osteopenia, a dense zone of provisional calcification at the metaphysis (line of Frankel; arrow), metaphyseal spurs (Pelkan spur; arrowhead) and a lucent band adjacent to the line of Frankel (Trummerfeld zone

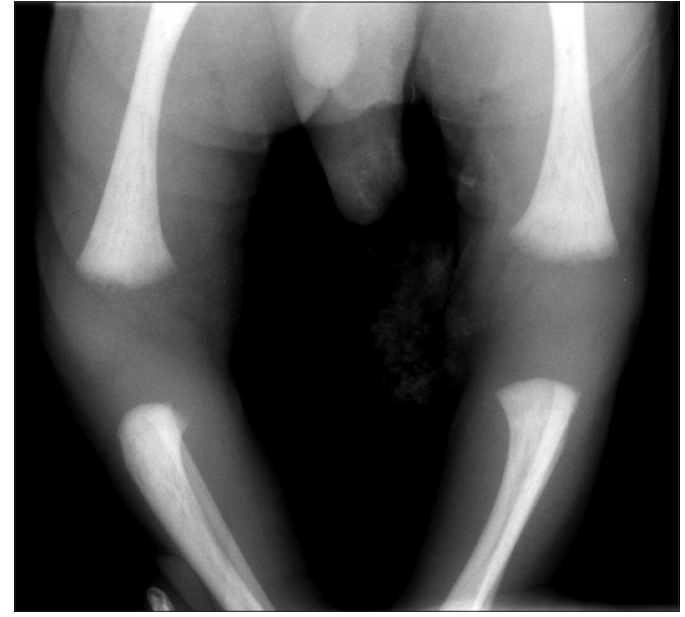

Fig. 2 Bilateral knee radiograph of a neonate with rubella shows longitudinally oriented sclerotic striations extending from the metaphysis of both distal femurs and proximal tibias, giving rise to a 'celery stalk' appearance.

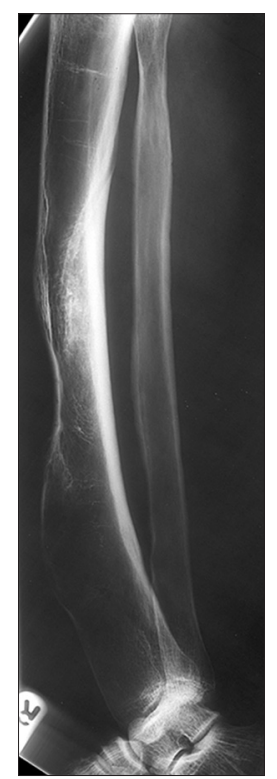

Fig. 3 Plain radiograph of the right tibia-fibula shows anterior bowing of the right tibia at its mid diaphysis with associated cortical thickening, classically known as the 'sabre shin' deformity, often found as a late manifestation of congenital syphilis.

of lucency; faintly seen near the line of Frankel). Small epiphyses with sharply sclerotic margins are also present (Wimberger ring sign; asterisk). Areas of subperiosteal swelling may be present due to subperiosteal haemorrhage and infarction (not seen).

\section{MACRORADIOGRAPHY}

A middle-aged woman presented with pain in the left hand. In Fig. 5, follow-up radiography using the macroradiography technique reveals the normal appearance of bony structures without evidence of fracture, bony erosion or periosteal reaction. As opposed to optical enlargement, macroradiography alters geometric factors during radiograph acquisition to increase the magnification of an image. ${ }^{(5)}$ This enhances visualisation of detail within the area of concern. Improved resolution of the cortical margins and bony trabeculae allows for better detection of fractures or osteolysis as well as more accurate assessment 


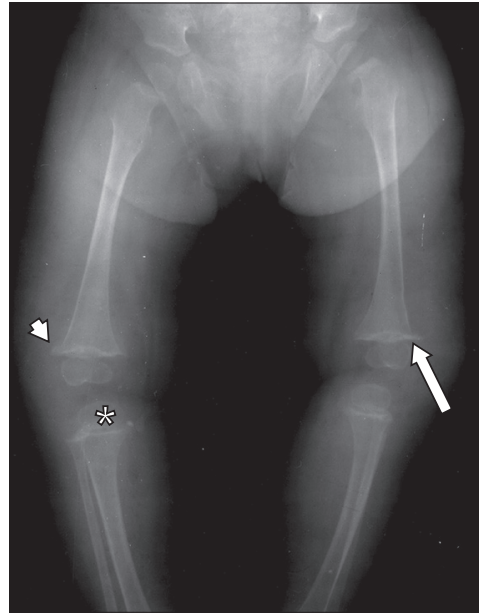

Fig. 4 Radiograph of the lower limbs donated by the University of Kentucky shows typical radiological findings of hypovitaminosis $\mathrm{C}$, commonly known as scurvy, including the line of Frankel (arrow), also known as the 'white line of Frankel', Pelkan spur (arrowhead) and the Trummerfeld zone of lucency (faintly seen lucent band adjacent and directly cranial to the line of Frankel). The Wimberger ring sign is present (asterisk).

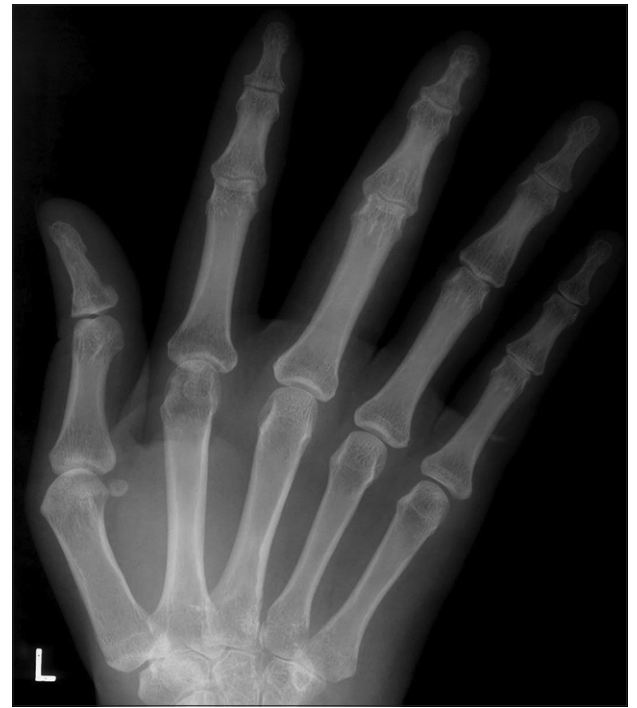

Fig. 5 Follow-up radiograph using macroradiography shows the normal appearance of bony structures without evidence of fracture, bony erosion or periosteal reaction.
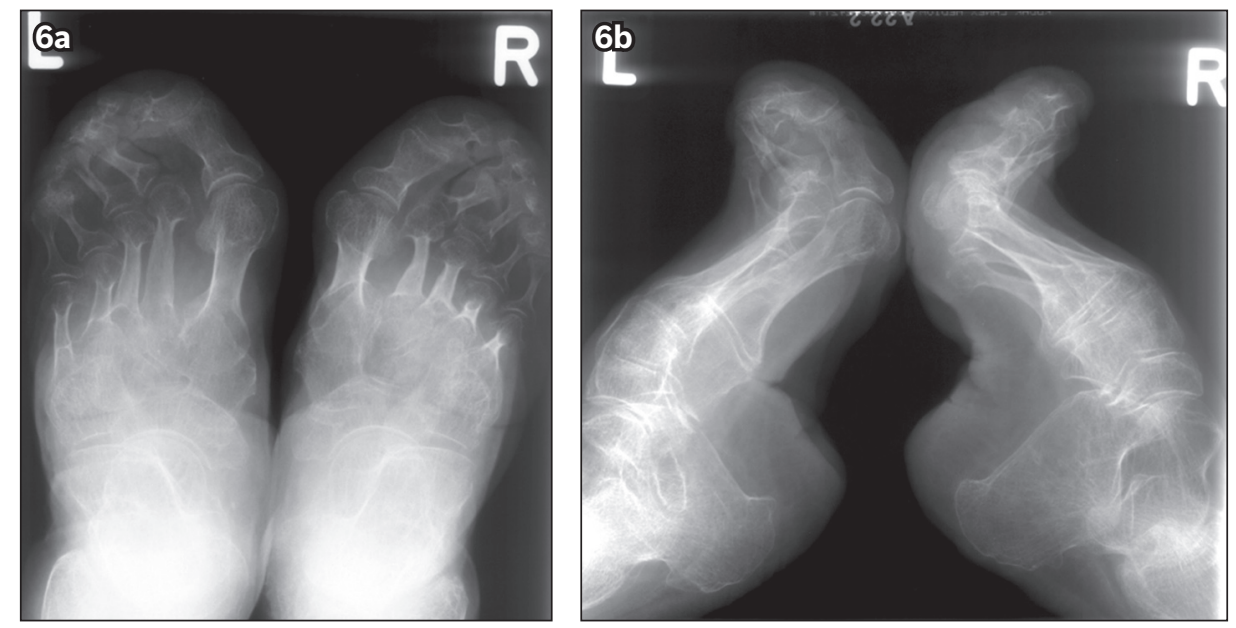

Fig. 6 Radiographs of the feet in (a) anteroposterior and (b) lateral view show marked deformity with significant pes cavus, exaggeration of the arches, a vertical orientation of the calcanei, and foreshortening of the feet, typical of foot binding as a child.

of silicosis in the chest. Evaluation of several niche regions including the carpus, petrous bones and orbits has also been described in the literature. In current practice, macroradiography has largely been replaced by digital radiography (allowing for digital image manipulation); computed tomography (CT), including dual-energy systems; and magnetic resonance (MR) imaging.

\section{BOUND FEET}

A 70-year-old Chinese woman presented with bilateral foot pain. Radiographs of her feet (Fig. 6) show marked deformity with significant pes cavus, exaggeration of the arches, a vertical orientation of the calcanei, and foreshortening of the feet. This appearance is typical of foot binding as a child. Originating in China between the Song and Tang dynasties (907-960) among those of higher socioeconomic status, the feet of girls aged 2-9 years were broken and bound with bandages to keep them small at 3-4 inches in size. Bound feet were seen as a symbol of status and beauty, and this procedure was performed even until the later part of the 19th century. In Singapore and Malaya, the practice was continued by Chinese migrants and their wives. Eventually, societal changes such as the provision of opportunities for the education of women led to the condemnation and eventual banning of this practice in China and Singapore.

\section{PELVIMETRY}

Pelvimetry is the assessment of the pelvic dimensions and volume through clinical examination and/or imaging. It was performed in women with suspected cephalopelvic disproportion (CPD) to identify pregnancies that may require Caesarean section. ${ }^{(6,7)}$ An example of pelvimetry is shown in Fig. 7. The incidence of CPD has anecdotally decreased in Singapore since its early history due to improved nutrition and resultant increased maternal height.

\section{PLACENTA PRAEVIA}

Placenta praevia denotes an abnormal low-lying placenta positioned close to or covering the internal cervical os. It confers 


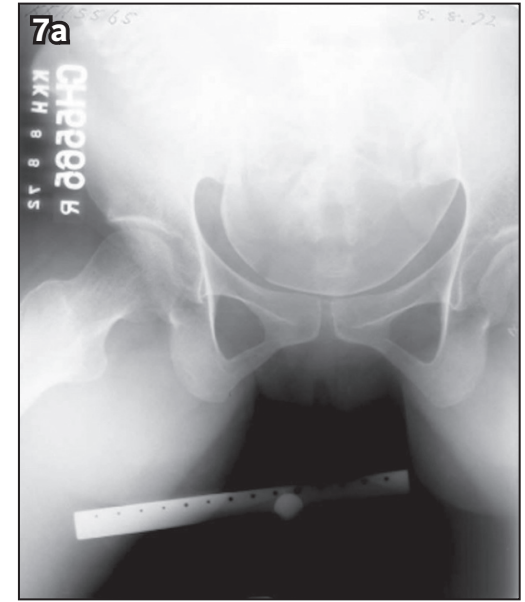

Zes

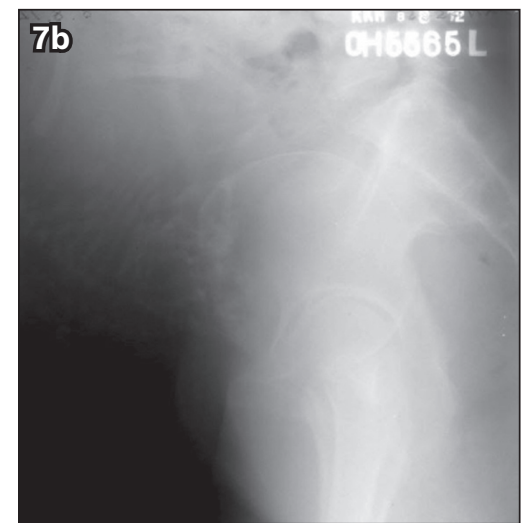

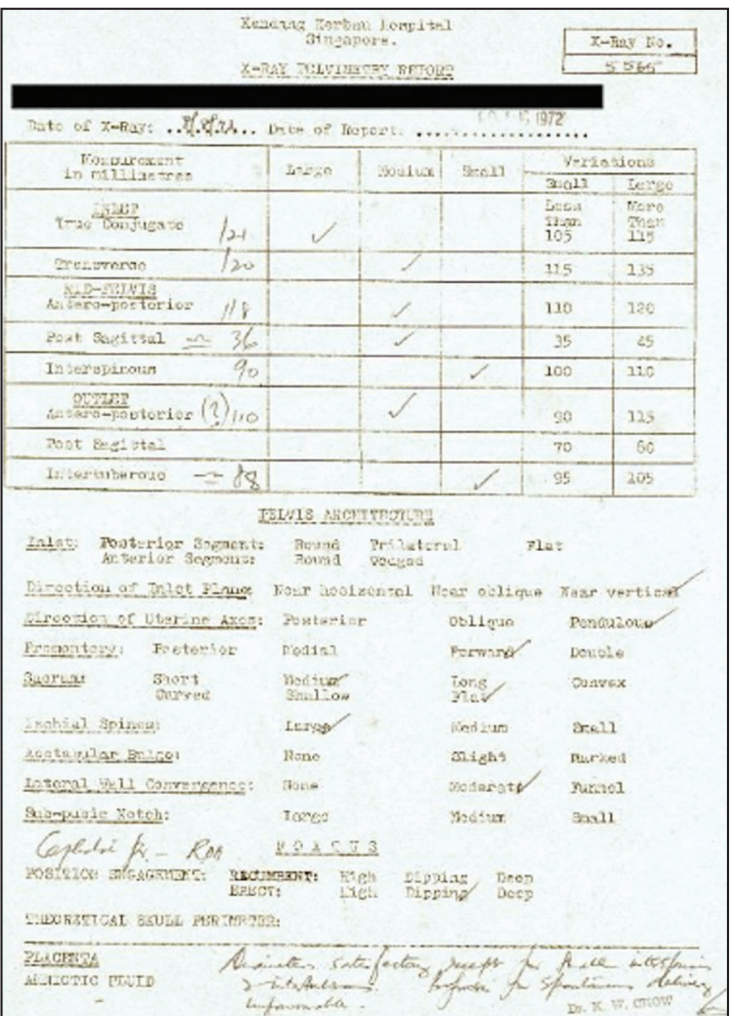

Fig. 7 (a) Anterior and (b) lateral radiographs of the pelvis show typical views for pelvimetry. A ruler for scale should be present in (b) but was not included in the original image. (c) Image shows the pelvimetry report detailing the pelvic measurements, pelvis architecture, fetal position and description of the placenta.

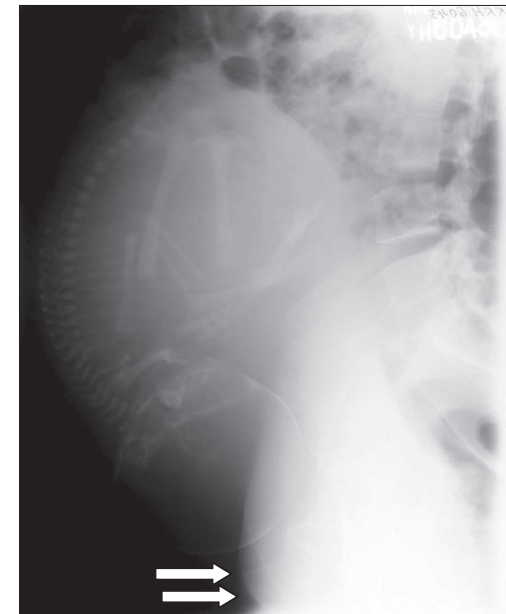

Fig. 8 Radiograph performed 15 minutes after the administration of intravenous contrast shows the presence of placenta praevia, as evidenced by an enhancing soft tissue mass (arrows) adjacent to the internal os.

a higher risk of potentially life-threatening massive antepartum haemorrhage, especially in a complete placenta praevia, and Caesarean section should be performed in this instance. Fig. 8 shows the presence of placenta praevia, as evidenced by an enhancing soft tissue mass (arrows) adjacent to the internal os on a radiograph performed 15 minutes after the administration of intravenous contrast. Radiography as a method of investigation, with its attendant risks of ionising radiation to mother and child, fell out of favour following the advent of sonography in obstetrics

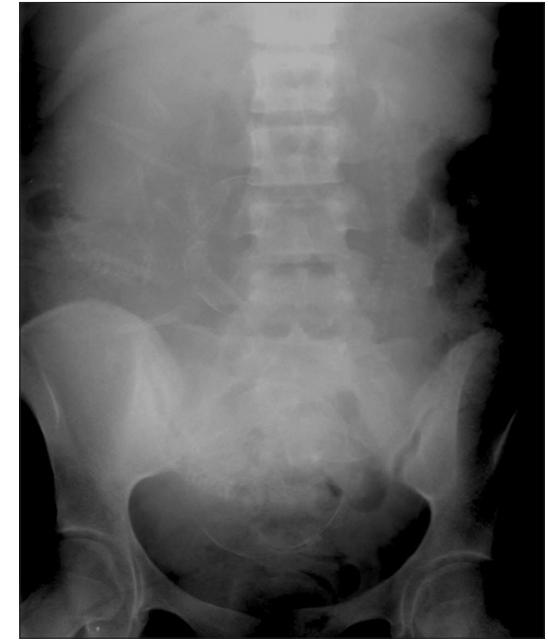

Fig. 9 Abdominal radiograph in a pregnant woman shows the presence of triplets, with two of the fetuses in breech presentation.

and gynaecology, which was pioneered in 1958 by Drs lan Donald, John McVicar and Tom Brown. ${ }^{(8)}$

\section{TRIPLETS}

Abdominal radiograph (Fig. 9) in a pregnant woman demonstrates the presence of triplets with two fetuses in breech presentation. Radiography was used in the pre-ultrasonography era to investigate for the presence of multiple pregnancies in a pregnant patient with a large-for-date uterus. 


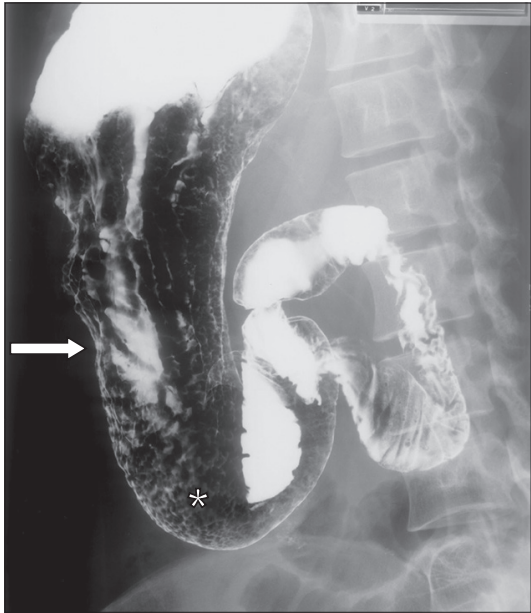

Fig. 10 Barium upper gastrointestinal tract study shows thickened lobulated and nodular folds in the gastric body suggestive of gastritis (arrow). A prominent areae gastricae pattern (asterisk) of the gastric antrum mucosa is noted, as seen in the setting of acid hypersecretion.

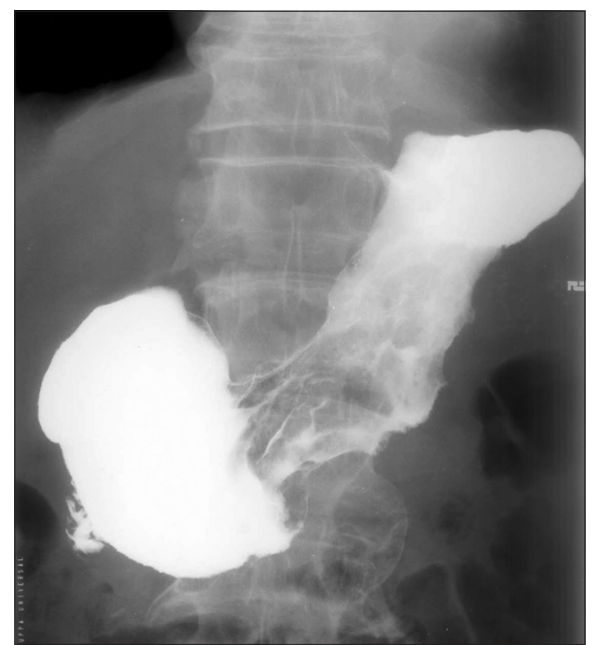

Fig. 11 Double-contrast barium study of a patient with gastric carcinoma shows absence of the normal gastric mucosal folds and suboptimal distension of the gastric body, known as a 'linitis plastica' appearance.
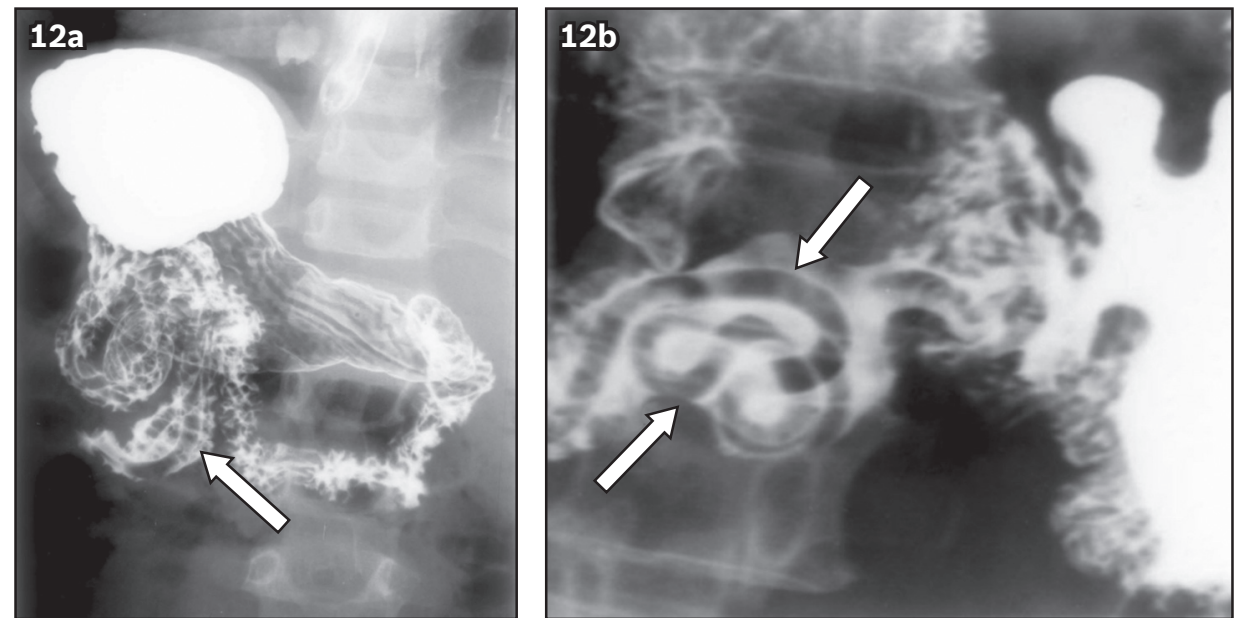

Fig. 12 ( $a$ \& b) Images from a barium meal study show several tubular filling defects (arrows) within the proximal small bowel, most clearly demonstrated in the proximal jejunum on (b) the magnified spot image, indicating the presence of Ascaris lumbricoides infestation.

\section{GASTRITIS}

The barium upper gastrointestinal tract (Gl) study in Fig. 10 shows thickened, lobulated and nodular folds in the gastric body suggestive of gastritis (arrow). Prominence of the usual fine reticular appearance of the gastric antrum mucosa is noted. This is known as a prominent areae gastricae pattern (asterisk) and may be seen in the setting of acid hypersecretion.

Barium upper Gl studies have been largely superseded by other endoscopic and imaging tests such as endoscopy, manometry and $\mathrm{pH}$ monitoring. There is, however, still a limited role for this study in the setting of pharyngography and oesophagography in the assessment of dysphagia. ${ }^{(8)}$

\section{GASTRIC CANCER}

A patient underwent a double-contrast barium meal to investigate symptoms of early satiety and loss of weight. This study shows the absence of the normal gastric mucosal folds and suboptimal distension of the gastric body, known as a 'linitis plastica' appearance (Fig. 11). These imaging features are attributed to diffuse thickening of the stomach wall and may be caused by neoplasm, granulomatous disease, gastric amyloidosis or scarring due to ingestion of corrosive liquids. Assessment of gastric motility for stiff or non-motile segments is also helpful to check if pathology is present. The patient was eventually diagnosed with gastric carcinoma. The present gold standard for diagnosis of gastric carcinoma is endoscopy, with $\mathrm{CT}$ also demonstrating an important role in detection and staging.

\section{ASCARIASIS}

Spot images of a barium meal (Fig. 12) show several tubular filling defects (arrows) within the proximal small bowel, most clearly demonstrated in the proximal jejunum on the magnified spot image. This indicates the presence of Ascaris lumbricoides infestation. Barium studies remain a useful radiology investigation, as they are easily accessible, quick and safe. A. lumbricoides is a major parasite species in soiltransmitted helminth infections. ${ }^{(9)}$ Ascariasis was commonplace in the early days of Singapore, affecting up to $61 \%$ of urban kampong populations. ${ }^{(10)}$ The subsequent eradication of ascariasis can be said to embody Singapore's progress from a developing to a developed nation. 


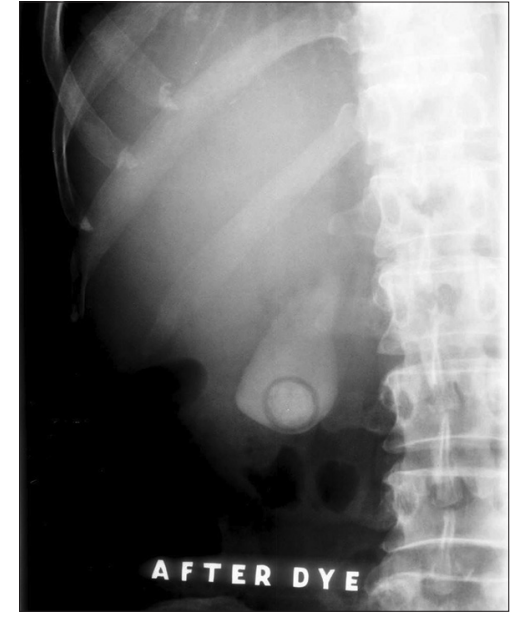

Fig. 13 Oral cholecystogram shows a filling defect within the gallbladder, consistent with a gallstone.

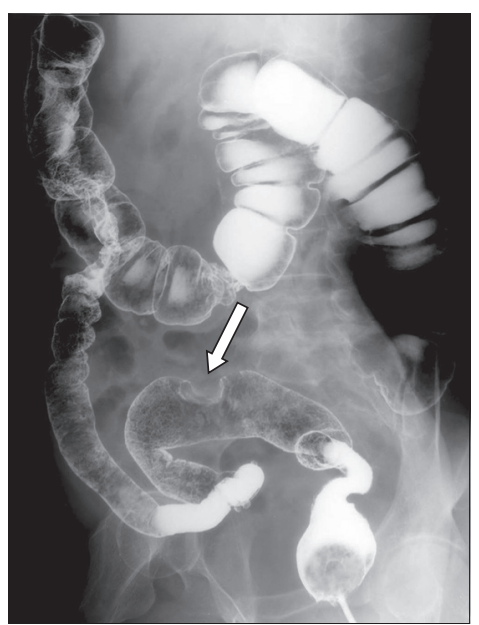

Fig. 15 Double-contrast barium enema image, performed for iron deficiency anaemia, shows a 'bowler-hat' sign, suggesting the presence of a sessile sigmoid polyp in the sigmoid colon (arrow).

\section{GALLSTONE ON ORAL CHOLECYSTOGRAM}

An oral cholecystogram study (Fig. 13) shows a filling defect within the gallbladder consistent with a gallstone. In this procedure, patients were first asked to have non-fatty meals prior to the study. Next, a contrast agent was administered orally; radiography was then performed after a time interval to assess for contrast filling of the gallbladder. A second dose of contrast was administered if the gallbladder failed to opacify the first time. The results of the study were thus divided into three categories: the presence of gallstones; the absence of gallstones; and a non-functional gallbladder, in which the gallbladder failed to opacify after the second contrast administration. Ultrasonography has since superseded the oral cholecystogram to become the primary modality for the detection of gallstones. A study from Singapore showed that ultrasonography obtained superior results and could be performed at the bedside while avoiding radiation or contrast media exposure. ${ }^{(11)}$

\section{CROHN'S DISEASE}

A small bowel follow-through study (Fig. 14) was performed for a patient with chronic diarrhoea and abdominal pain.
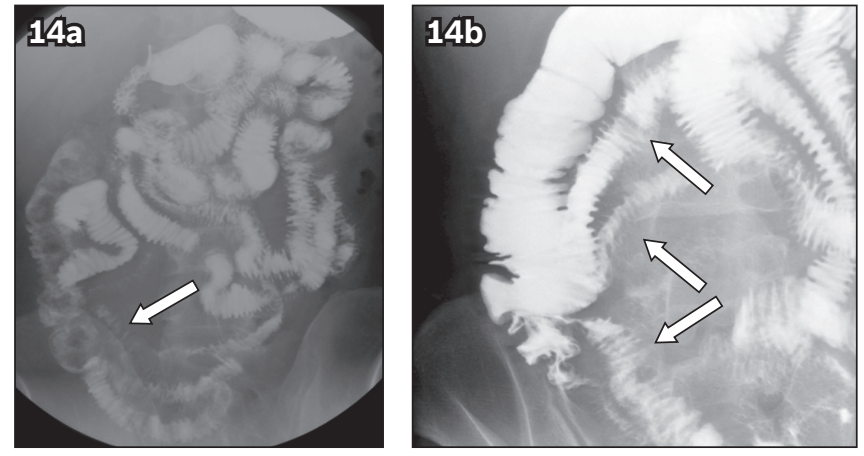

Fig. 14 (a) Small bowel iodinated contrast follow-through study with (b) spot views of the right iliac fossa in a patient with chronic diarrhoea and abdominal pain shows the presence of an abnormal pattern of luminal contrast opacification (arrows) indicating deep ulcerations, longitudinal fissures and thickened folds in the bowel wall. Separation of bowel loops are also present. The overall features are compatible with Crohn's disease.

It demonstrates an abnormal pattern of luminal contrast opacification indicating deep ulcerations, longitudinal fissures and thickened folds in the small bowel wall (arrows). There is also separation of the small bowel loops due to the presence of transmural inflammation as well as the presence of stricturing of the terminal ileum. These imaging features are compatible with Crohn's disease. Currently, the small bowel follow-through study has been superseded by small bowel MR/CT enterography due to the greater diagnostic accuracy. MR enterography also does not produce ionising radiation, with its attendant side effects, and allows for more frequent imaging to evaluate disease status.

\section{MALIGNANT SIGMOID POLYP}

A double-contrast barium enema (Fig. 15) was performed for iron deficiency anaemia. A 'bowler-hat' sign suggesting the presence of a sessile sigmoid polyp was seen in the sigmoid colon (arrow). This radiological appearance arises from contrast coating on the body of the polyp as well as the recess between its base and the colonic wall. Rarely, other intraluminal objects such as stool or air bubbles can mimic this appearance. However, these entities are mobile and can be easily differentiated from polyps during real time fluoroscopy. There is a decreasing role for barium enema studies in present day radiological practice, as they have largely been replaced by CT colonography as a radiological screening tool due to the superior sensitivity of CT. ${ }^{(12)}$

\section{ASCENDING COLON CANCER}

A 55-year-old man presented with a one-month history of change in bowel habits. Spot radiograph from a single-contrast barium enema (Fig. 16) demonstrates an annular 'apple-core' lesion (arrows) narrowing the lumen of the colon, consistent with a diagnosis of ascending colon cancer. Contrast enemas were first introduced in Singapore in the 1920s. ${ }^{(13)}$ This dynamic, timeconsuming exam required the patient to physically turn on the fluoroscopic table, using gravity to manipulate the barium column from the rectum to the caecum. The double-contrast technique introduced in the 1970s added an additional step to distend the bowel lumen with gas for improved visualisation, increasing the sensitivity of detection to $96 \%$ for polyps that were larger than 


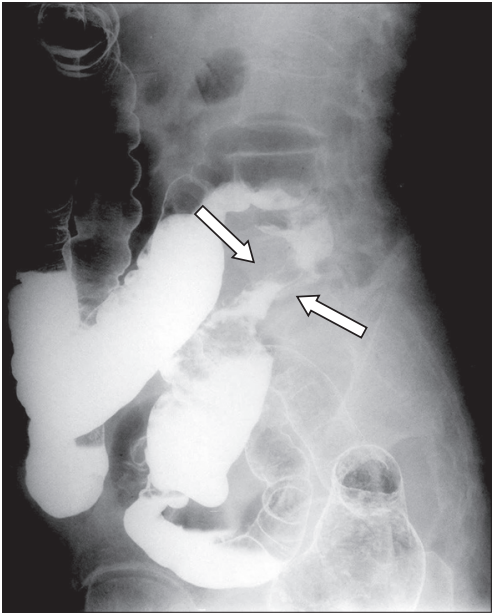

Fig. 16 Spot radiograph from a single contrast barium enema shows an annular 'apple-core' lesion (arrows) narrowing the lumen of the colon, consistent with a diagnosis of ascending colon cancer.

$1 \mathrm{~cm}$ in diameter. Barium enemas have now been superseded as a radiological examination by $\mathrm{CT}$ colonoscopy, which is able to produce three-dimensional images of the colon in less than 30 seconds while still maintaining the use of gas insufflation used in the double-contrast technique for lesion delineation.

\section{LYMPHANGIOGRAM}

A lymphangiogram (Fig. 17) in a 25-year-old woman with fever and night sweats shows normal contrast opacification of the retroperitoneal and iliac lymph nodes. In this technique, a fatty acid contrast is injected into the tissues of the foot at the first webspace in order to opacify the lymphatic vessels and nodes. Lymphangiography was often used to evaluate abdominal involvement in tuberculosis, as well as to evaluate treatment response in lymphoma. ${ }^{(14)}$ This technique was introduced in Singapore by Dr Boey Hong Khim, ${ }^{(15)}$ a pioneer in local radiology, former head of department at Tan Tock Seng Hospital and Mount Elizabeth Hospital, and founding member of the Singapore Radiological Society and ASEAN Association of Radiology. Dr Boey was known for his modifications of this technique, namely the pre-injection of methylene blue to aid with localisation of the lymphatics, and the use of weighted syringes to achieve the injection pressures necessary for this procedure.

Lymphangiography has since been superseded by CT and positron emission tomography. However, it remains diagnostically more sensitive than $\mathrm{CT}$, as it is able to demonstrate derangements in the internal architecture of normal-sized lymph nodes compared with $\mathrm{CT}$, which demonstrates only size. In a sense, the technique lives on, as the same method of injection is currently used in lymphoscintigraphy for the investigation of lymphatic obstruction. This nuclear medicine procedure is becoming more common with the development of reconstruction techniques in plastic surgery for lymphatic obstruction.

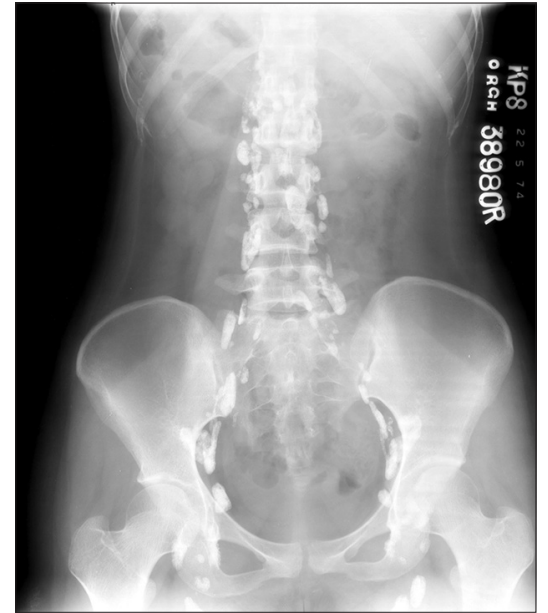

Fig. 17 Lymphangiogram of a woman with fever and night sweats shows normal contrast opacification of the retroperitoneal and iliac lymph nodes.

\section{ACKNOWLEDGEMENTS}

The authors would like to acknowledge the staff of the Department of Diagnostic and Interventional Imaging, KK Women's and Children's Hospital, Singapore, for their assistance in digitising the hard copy films from the SingHealth Radiology Archives.

\section{REFERENCES}

1. Tan MBW, Tan KP, Beh JCY, et al. SingHealth Radiology Archives pictorial essay Part 1: cardiovascular, respiratory and neurological cases. Singapore Med J 2020; 633-40.

2. Ang LW, Chua LT, James L, Goh KT. Epidemiological surveillance and control of rubella in Singapore, 1991-2007. Ann Acad Med Singapore 2010; 39:95-101.

3. Morton RS. The problem of venereal diseases in Singapore. Br J Vener Dis 1971; 47:48-51.

4. Chang CY, Rosenthal DI, Mitchell DM, et al. Imaging findings of metabolic bone disease. Radiographics 2016; 36:1871-87.

5. Davidson RA, Bowman S. Macroradiography using conventional radiographic X-ray equipment. Br J Radiol 2002; 75:831-6.

6. Barron LR, Hill RO, Linkletter AM. X-ray pelvimetry. Can Med Assoc J 1964; 91:1209-12.

7. Toh-Adam R, Srisupundit K, Tongsong T. Short stature as an independent risk factor for cephalopelvic disproportion in a country of relatively small-sized mothers. Arch Gynecol Obstet 2012; 285:1513-6.

8. Levine MS, Rubesin SE, Laufer I. Barium studies in modern radiology: do they have a role? Radiology 2009; 250:18-22.

9. Dunn JC, Turner HC, Tun A, Anderson RM. Epidemiological surveys of, and research on, soil-transmitted helminths in Southeast Asia: a systematic review. Parasit Vectors 2016; 9:31.

10. Desowitz R, Zaman V, Ng WK. The incidence of intestinal parasites in various communities of Singapore island. Singapore Med J 1961; 2:91-3.

11. Tan JS, Chee SG, Tan KP, Khoo TK. Comparison of accuracy of ultrasonography and oral cholecystography in the diagnosis of cholelithiasis. Singapore Med J 1988; 29:485-8.

12. Halligan S, Wooldrage K, Dadswell E, et al. Computed tomographic colonography versus barium enema for diagnosis of colorectal cancer or large polyps in symptomatic patients (SIGGAR): a multicentre randomised trial. Lancet 2013; 381:1185-93.

13. Celebrating 50 years of illuminating lives: Singapore Society of Radiographers: golden jubilee, 1958-2008. Hong CY, Ler MBL, eds. Singapore: Singapore Society of Radiographers, 2008.

14. Guermazi A, Brice P, Hennequin C, Sarfati E. Lymphography: an old technique retains its usefulness. Radiographics 2003; 23:1541-60.

15. Chow KW. Citation on Dr. Boey Hong Khim 2009 FY Khoo Memorial Lecturer. Ann Acad Med Singapore 2009; 38:660-2. 


\section{SINGAPORE MEDICAL COUNCIL CATEGORY 3B CME PROGRAMME} (Code SMJ 202101B)

Question 1. Regarding lead poisoning:

(a) It is associated with lucent metaphyseal bands.

(b) The use of lead in paint was banned since 1978 .

(c) Lead increases osteoclastic activity.

(d) Lead increases osteoblastic activity.

Question 2. Regarding scurvy:

(a) It is associated with increased Vitamin C intake.

(b) It is due to defective collagen synthesis.

(c) Radiological findings include osteopenia.

(d) It may be associated with subperiosteal haemorrhage and bone infarction.

Question 3. Regarding gastritis:

(a) Thickened, nodular and lobulated rugae are suggestive of gastritis.

(b) Prominence of the reticular appearance of the gastric antrum mucosa may be seen in the setting of acid hypersecretion.

(c) Fluoroscopic upper gastrointestinal (Gl) tract studies to investigate for gastritis have mostly been superseded by endoscopy.

(d) Fluoroscopic upper Gl studies have a limited role in the setting in the setting of pharyngography and oesophagography for the assessment of dysphagia.

Question 4. The following conditions are associated with a 'linitis plastica' appearance of the stomach:

(a) Granulomatous disease.

(b) Neoplasm.

(c) Achlasia.

(d) Scarring due to corrosive liquid ingestion.

Question 5. Regarding Crohn's disease:

(a) Small bowel follow-through has been superseded by small bowel magnetic resonance (MR)/ computed tomography (CT) enterography due to greater diagnostic accuracy.

(b) MR enterography has been superseded by small bowel MR/CT enterography due to greater diagnostic accuracy.

(c) In small bowel follow-through fluoroscopic studies, deep ulceration, longitudinal fissures and thickened bowel wall are suggestive of Crohn's disease.

(d) Patients commonly present with vomiting and haematemesis.

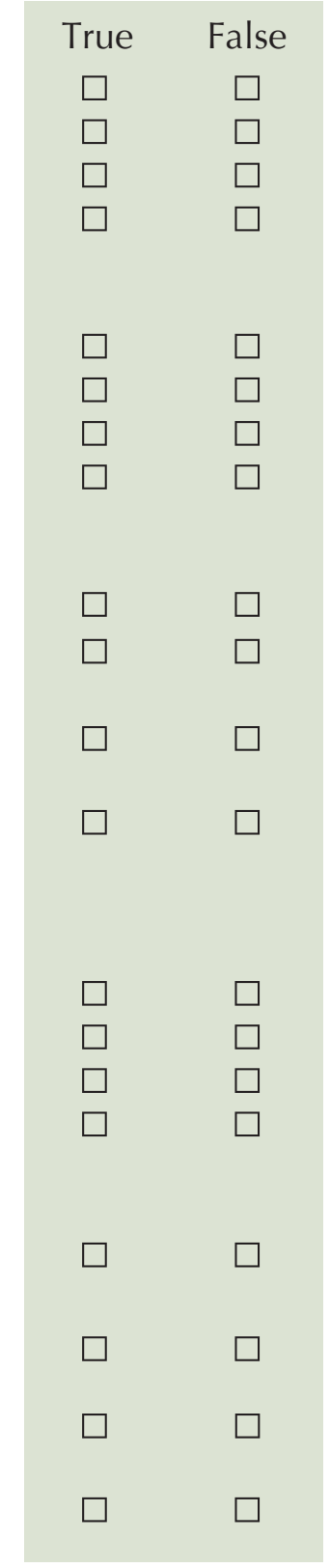

\section{Doctor's particulars:}

Name in full:

Specialty:
MCR no.:

Email:

\section{SUBMISSION INSTRUCTIONS:}

Visit the SMJ website: http://www.smj.org.sg/current-issue and select the appropriate quiz. You will be redirected to the SMA login page.

For SMA member: (1) Log in with your username and password (if you do not know your password, please click on 'Forgot your password?'). (2) Select your answers for each quiz and click 'Submit'.

For non-SMA member: (1) Create an SMJ CME account, or log in with your SMJ CME username and password (for returning users). (2) Make payment of SGD 21.40 (inclusive of $7 \%$ GST) via PayPal to access this month's quizzes. (3) Select your answers for each quiz and click 'Submit'.

\section{RESULTS:}

(1) Answers will be published online in the SMJ March 2021 issue. (2) The MCR numbers of successful candidates will be posted online at the SMJ website by 17 March 2021. (3) Passing mark is $60 \%$. No mark will be deducted for incorrect answers. (4) The SMJ editorial office will submit the list of successful candidates to the Singapore Medical Council. (5) One CME point is awarded for successful candidates. (6) SMC credits CME points according to the month of publication of the CME article (i.e. points awarded for a quiz published in the January 2021 issue will be credited for the month of January 2021, even if the deadline is in March 2021).

Deadline for submission (January 2021 SMJ 3B CME programme): 12 noon, 10 March 2021. 